and may require decompressive surgery. ${ }^{67} \mathrm{CT}$ scanning or MRI may reveal the characteristic proliferation of restrosternal tissue, but a biopsy specimen may be required to exclude malignancy. A biopsy specimen was not taken in this case due to the overall poor health of the patient.

As far as we are aware, there are no previous reports of sinus formation occurring in $\mathrm{SCCH}$, either over the affected area or peripherally.

The differential diagnosis of $\mathrm{SCCH}$ includes malignancies such as plasmacytoma involving the sternum and metastatic thyroid or oral cavity carcinomas. Non-malignant causes include diffuse idiopathic skeletal hyperostosis, Paget's disease condensing osteitis, and osteomyelitis.

Treatment is usually conservative as no specific therapy has been shown to alter the course of the disease. Following stage II, which may last for many years, the final stage III is characterised by ankylosis of the affected joints and ossification of the cartilage of the ribs. Limited symptomatic relief may be gained with the use of non-steroidal anti-inflammatory agents and corticosteroids.

The authors wish to thank Mr A Jones, Dr J Verbov, Dr H Carty.

1 Sasaki T. A case with osteomyelitis of the bilateral clavicles as in Seikeigeka 1967;2:333-7 (in Japanese).

2 Chigira $M$, Maehara $S$, Nagase $M$, Ogimi $T$, Udagawa $E$. Sternoclavicular hyperostosis. A report of nineteen cases with special reference to etiology and treatment. $\mathcal{F}$ Bon oint Surg $[\mathrm{Am}]$ 1986;68:103-12.

3 Kholer H, Uehlinger E, Kutzner J, et al. Sternocostoclavicular hyperostosis: painful swelling of the sternum, clavicles and upper ribs. Report of two new cases. Ann Intern Med 1977; 87:192-4.

4 Fritz P, Baldauf G, Wilke HJ, Reitter I. Sternocostoclavicular hyperostosis: its progression and radiological features. A study of 12 cases. Ann Rheum Dis 1992;51:658-64.

5 Resnick D. Sternocostoclavicular hyperostosis. AfR 1980; 135:1278-80.

6 Jirik FR, Stein HB, Chalmers A. Clavicular hyperostosis with enthesopathy, hypergammaglobulinaemia and thoracic outenthesopathy, hypergammaglobulinaemia and thor.

7 Haenel LC, Bradway WR, Constantini PJ. Thrombophlebitis complicating sternocostoclavicular hyperostosis. Postgrad Med F 1980;68:113-8.

\section{Lymphangitis carcinomatosa complicating primary malignant peritoneal mesothelioma}

Paul S Craft, Martin S Reading, Sanjiv Jain, Ross A O’Neil

\begin{abstract}
A patient with malignant peritoneal mesothelioma and a diffuse pulmonary infiltrate is described. Computed tomographic scanning suggested lymphangitis carcinomatosa. This was confirmed on transbronchial biopsy to be due to metastatic mesothelioma.

(Thorax 1996;51:552-553)
\end{abstract}

Keywords: peritoneal mesothelioma, lymphangitis carcinomatosa, metastasis.

Department

$S$ Jain

Radiology Department R A O'Neil

Woden Valley Hospital, Canberra, ACT 2605, Australia

Correspondence to: Dr P S Craft.

Received 5 January 1995 Accepted for publication 4 April 1995 an annual incidence of between 0.7 and per million. ${ }^{12}$ Increasing incidence has been reported in many countries including the United States and, in particular, Australia. ${ }^{13}$ The disease is strongly linked to asbestos exposure, particularly crocidolite. Approximately $10 \%$ of mesotheliomas arise from the peri- toneum. ${ }^{4}$ Lymphangitis carcinomatosa is characterised histologically by diffuse permeation of tumour cells within pulmonary lymphatics. We are not aware of any previously reported examples of lymphangitis carcinomatosa due to malignant mesothelioma.

\section{Case report}

A 52 year old man presented with a two month history of weight loss and upper abdominal pain. There was a history of asbestos exposure 20 years earlier. A chest radiograph, taken at the onset of symptoms, was normal. An abdominal computed tomographic (CT) scan showed a diffuse omental mass. Needle biopsy yielded cytologically abnormal mesothelial cells consistent with mesothelioma.

One month later the patient developed a non-productive cough and exertional dyspnoea. Auscultation of the lung fields revealed bilateral fine basal crackles. The chest radiograph on this occasion showed a widespread reticulonodular pattern with septal thickening. A high resolution CT scan of the thorax revealed diffuse nodular thickening with polygon formation (fig 1). Bronchoscopic examination was normal. Transbronchial biopsy specimens showed abnormal epithelioid malignant cells with mild nuclear pleomorphism and prominent nucleoli. These cells were identical to those obtained from the previous omental needle biopsy. Ultrastructurally they showed long branching microvilli consistent with mesothelioma (fig 2). Cytotoxic chemotherapy with cisplatin and doxorubicin was associated with stable disease for three months. The patient died eight months after presentation from respiratory failure due to progressive disease. 




Figure 1 High resolution computed tomographic scan of the thorax showing diffuse interstitial thickening. Peripheral wedge densities are seen in the apical segment of the left upper lobe.



Figure 2 Electron micrograph of a malignant cell from a transbronchial biopsy specimen with long microvilli (length:diameter >20:1). Inset: branching microvilli.

\section{Discussion}

The clinical course of abdominal mesothelioma is usually dominated by direct invasion of adjacent structures by the primary tumour. Metastatic disease complicating peri- toneal mesothelioma is uncommon, even in necroscopic studies. ${ }^{5}$ In contrast, frequent metastases to lymph nodes, lung, liver, and brain have been reported in patients with pleural mesothelioma. ${ }^{6}$ Miliary pulmonary metastases without lymphangitis have been reported as the initial manifestation of pleural mesothelioma. ${ }^{7}$

Lymphangitis carcinomatosa has been associated with many forms of malignancy and, in particular, carcinomas of breast, stomach, lung, pancreas, and prostate. The radiological features of this case are those classically described in lymphangitis carcinomatosa. ${ }^{8}$

Management of peritoneal malignant mesothelioma remains difficult and survival following diagnosis rarely exceeds one year. ${ }^{5}$ Occasional long term survivors are seen following surgical resection. ${ }^{9}$ Only modest activity has been seen in patients with pleural or peritoneal mesothelioma with cytotoxic chemotherapy. The prognosis of patients with metastatic disease, even confined to regional lymph nodes, is particularly poor. ${ }^{10}$

With the increasing incidence of malignant mesothelioma, presentations including metastatic disease will become more clinically important. In patients with lymphangitis carcinomatosa underlying malignant mesothelioma should be considered. Electron microscopic examination of transbronchial biopsy material may allow the diagnosis to be rapidly achieved.

1 Vogelzang NJ. Malignant mesothelioma: diagnostic and management strategies for 1992. Semin Oncol 1992, 19(Suppl 11):64-71.

2 Musk AW, Dolin PJ, Armstrong BK, Ford JM, de Klerk NH Hobbs MS. The incidence of malignant mesothelioma in Australia, 1947-1980. Med f Aust 1989;150:242-3.

3 Ferguson D. Malignant mesothelioma - the rising epidemic Med $\mathcal{F}$ Aust 1989;150:233-5.

4 Driscoll TR, Baker GJ, Daniels S, Lee J, Thompson R, Ferguson DA, et al. Clinical aspects of malignant mesothelioma in Australia. Aust NZ $\mathcal{F}$ Med 1993;23:19-25.

5 van Gelder T, Hoogsteden HC, Versnel MA, de Beer PH, Vandenbroucke JP, Planteydt HT. Malignant peritoneal mesothelioma: a series of 19 cases. Digestion 1989;43: $222-7$.

6 Ruffie P, Feld R, Minkin S, Cormier Y, Boutan-Laroze A Ginsberg R, et al. Diffuse malignant mesothelioma of the pleura in Ontario and Quebec: a retrospective study of 332 patients. $\mathcal{F}$ Clin Oncol $1989 ; 7: 1157-68$.

7 Musk AW, Dewar J, Shilkin KB, Whitaker D. Miliary spread of malignant pleural mesothelioma without a clinically identifiable pleural tumour. Aust NZ F Med 1991;21 $460-2$

8 Stein MG, Mayo J, Muller N, Aberle DR, Webb WR, Gamsu G. Pulmonary lymphangitic spread of carcinoma: appearance on CT scans. Radiology 1987;162:371-5.

9 Asensio JA, Goldblatt P, Thomford NR. Primary malignant peritoneal mesothelioma. Arch Surg 1990;125:1477-81.

10 Sugarbaker DJ, Strauss GM, Lynch TJ, Richards W, Mentzer SJ, Lee TH, et al. Node status has prognostic significance in the multimodality therapy of diffuse, malignant mesothelioma. F Clin Oncol 1993;11:1172-8. 